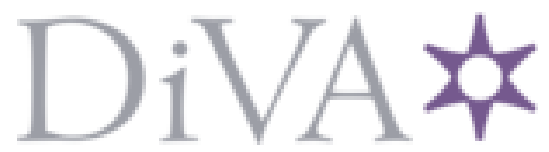

http://www.diva-portal.org

\title{
Postprint
}

This is the accepted version of a paper published in European Business Review. This paper has been peer-reviewed but does not include the final publisher proof-corrections or journal pagination.

Citation for the original published paper (version of record):

Eriksson, D. (2016)

The role of moral disengagement in supply chain management research.

European Business Review, 28(3): 274-284

https://doi.org/10.1108/EBR-05-2015-0047

Access to the published version may require subscription.

N.B. When citing this work, cite the original published paper.

Permanent link to this version:

http://urn.kb.se/resolve?urn=urn:nbn:se:hj:diva-34076 


\section{The Role of Moral Disengagement in Supply Chain Management Research}

Paper Type: Conceptual

\section{Structured abstract}

Purpose: To elucidate the role of moral disengagement in supply chain management (SCM) research, and challenges if the theory is to be used outside of its limitations.

Design/methodology/approach: Conceptual paper based on how Bandura has developed and used moral disengagement.

Findings: Moral disengagement can be used in SCM research. The theory is not to be applied to the supply chain itself, but SCM can be seen as the environment that is part of a reciprocal exchange that shapes human behavior.

Research limitations/implications: The paper suggests a new theory to better understand business ethics, corporate social responsibility, and sustainability in SCM. Further, the paper outlines how the theory should be used, and some challenges that still remain.

\section{Practical implications:}

Originality/value: SCM researchers are given support on how to transfer a theory from psychology to SCM, which could help to progress several areas of the research field. The paper also highlights an inconsistency in the use of the theory, and gives support to how it should be used in SCM research.

Keywords: Bandura; business; disengagement; ethics; moral; organization; supply chain management (SCM) 


\section{Elucidating the Role of Moral Disengagement in Supply Chain Management Research}

\section{Introduction}

In recent years there has been an increased attention on corporate social responsibility and sustainability in supply chain management (SCM) (e.g. Fassin and Van Rossem, 2009; Høgevold, 2011; Aguinis and Glavas, 2012). Despite insightful research focusing on the importance of, for example, collaboration between stakeholders (Walker and Laplume, 2014) and transparency (Hutchinson et al., 2012), the field still suffers from a lack of a theoretical foundation (e.g. Winter and Knemeyer, 2013). Aguinis and Glavas (2012) stress the need for understanding mechanisms that govern personal conduct, which could help to better understand misconduct. One established theory that targets such mechanisms, but has not yet gained recognition in SCM, is moral disengagement by Albert Bandura.

Bandura is considered to be the most eminent psychologist of the $20^{\text {th }}$ century still alive (Haggbloom et al., 2002). Bandura is most famous for social learning theory (Bandura, 1963), but has gained attention by researchers in areas related to SCM for the theory 'moral disengagement' (Bandura et al., 1996). While the use of moral disengagement in organizational research is relatively new (Samnani et al., 2014), several examples are found. These include consumer attitudes (Egan et al., 2015), unethical employee behavior (Martin et al., 2014), and counterproductive workplace behavior (Fida et al., 2014). However, the theory has still not made a breakthrough in SCM where it holds great potential for the intersection between the field itself and business ethics, corporate social responsibility, and sustainability (Eriksson and Svensson, 2014). Recently, a few authors have used moral disengagement in SCM research (e.g., Eriksson et al., 2013a; Eriksson et al., 2013b; Eriksson and Svensson, 2014; Egels-Zandén, 2015), but guidelines for how to actually use the theory in this research field are not yet established. By offering guidelines in an early stage of the theory adoption, this paper seeks to reduce potential future problems through misuse of the theory.

While both Bandura and moral disengagement are highly regarded, problems do exist with regard to how the theory is used in business-related research. One important problem is that moral disengagement is sometimes used on organizations, which might not be advisable. A better understanding of these problems is necessary to avoid confusion and misguidance if we wish to use the theory in SCM research. The purpose of this paper is to bring clarity into how moral disengagement can be used in SCM, and what the challenges are if it is used outside of this frame. The main research questions is:

$R Q:$ If the theory moral disengagement is to be used in supply chain management, what considerations are necessary?

To answer this question it is also necessary to understand how the theory is created, what it is intended for, if there are any uncertainties, and if there are other concerns that need attention.

\section{Method}

The investigation will be limited to articles published by Bandura in research journals where the article is centered on moral disengagement. This leaves out parts of the works published as books or chapters, but captures the body of literature readily available to researchers. Each 
reviewed paper will be briefly explained and quotes elucidating its view on the theory of moral disengagement will be presented. Three uses are to be expected. One where a consistent line is argued; a second with a main line is argued, but inconsistencies exist; and a third where multiple conflicting lines are argued. Statements from the articles that relate the theory to individuals or organizations have been collected in the review. References to the articles discussed are made as clear as possible to allow the reader to verify that a true picture of the used material is given in this paper.

In this article it has been chosen not to provide a detailed explanation of the theory itself, although a small introduction is available in Section 3, and parts of the theory are explained in Table 1. For more information the reader is referred to the works of Bandura. Also, authors using moral disengagement are not included except for some examples of the use of the theory and/or related concepts. Instead, this article lays a platform to elucidate how moral disengagement can be used, based on the foundation provided by Bandura. A separate literature review on authors referencing Bandura (1999) has been conducted (Eriksson, 2014, pp. 29-30). It showed that authors referencing (Bandura, 1999) accepted the theory, but did not continue refinement of the theory itself. Consequently, focusing on Bandura's papers alone should not provide a skewed explanation of the theory. One small remark on the theory was found in Treviño et al. (2006, p. 958), who state that "Research will be needed to better understand whether these same processes [moral disengagement] are anticipatory, post hoc, or both". This issue will be further elaborated in this paper. Finally, this paper will show inconsistencies, and areas in need of clarification based on Bandura's publications alone.

Several other theories and concepts can be used to understand morality in business and supply chain research. These include attachment theory (Chugh et al., 2014), cognitive dissonance (Festinger, 1957), demoralizing processes (Jensen, 2010), and moral approbation (Jones and Ryan, 1997). There are also several researchers who have investigated moral behavior in different well-known experiments, notably Milgram (1974) and Zimbardo (2007). While there certainly are options, there are two reasons why Bandura and moral disengagement are reviewed in this paper. Firstly, moral disengagement offers eight mechanisms that can be connected to the context of SCM, making it relatively easy to borrow into SCM. Secondly, the theory has been used in organizational research, and can be on the brink of gaining momentum in SCM.

\section{Global Supply Chains and Morality}

In this paper a supply chain is considered a chain, or network of organizations (cf. Cooper et al., 1997; Miemczyk et al., 2012). Depending on the sources it will sometimes be necessary to refer to a single organization, however, the organizations mentioned do not act alone, but are included in supply chains. The difference in scope is a result of varying units of analysis used by researchers. Supply chain research usually focuses on a dyad, a chain, or a network (Miemczyk et al., 2012), but a narrow focus does not exclude the organization from the rest of the chain. The management direction responsible for supply chains is called SCM. Sometimes it is considered a management of flows (Forrester, 1958), and sometimes as process management (Cooper et al., 1997). These chains are not confined to isolated geographical, or cultural islands, but span across several such regions (Lowson, 2001; Warburton and Stratton, 2002). Accordingly, it is reasonable to assume that a chain also spans across several different considerations of what is moral, which might appear to be a problem discussing morality in a supply chain. 
The definition of morality is long debated, evidenced by the fact that the debate was considered old in the $18^{\text {th }}$ century (cf. Hume, 1777, ch. 1). Discussing moral disengagement, Bandura addresses an individual's sense of right and wrong. Moral disengagement occurs when the individual is able to act in contrast to his or her morals, without feeling bad. The mechanisms by which one's morals are disengaged are the same across different geographical and cultural contexts, even though the individual's sense of morality may be different depending on these contexts. As such, moral disengagement can be used on each individual connected to a supply chain, as it only addresses how the specific individual is able to disengage morally, regardless of their morals.

\section{Moral Disengagement}

In this article five papers written by Bandura (Bandura, 1999; 2002; Bandura et al., 1996; 2000; 2001) are investigated in order to evaluate what role moral disengagement can have in supply chain research. Moral disengagement is related to social learning theory (Bandura, 1963). To understand behavior, Bandura (1978, p. 346) uses what is called reciprocal determinism, where "behavior, internal personal factors, and environmental influences all operate as interlocking determinants of each other [...] the process involves a triadic reciprocal interaction rather than a dyadic conjoint or dyadic bidirectional one”. Moral disengagement outlines eight mechanisms that separate moral reactions from inhumane conduct, allowing an individual to avoid self-condemnation for what is considered immoral (Bandura et al., 1996; Bandura, 1999). The mechanisms are: moral justification, euphemistic labeling, advantageous comparison, displacement of responsibility, diffusion of responsibility, disregard or distortion of consequences, dehumanization, and attribution of blame. As such, the theory includes behavior, cognitive processes, and environmental influences. Below follows an investigation into how Bandura has both developed and used the theory.

\subsection{Development of the Theory: Focus on Individuals, and Context}

While earlier sources are available, Bandura et al. (1996) author the first journal publication focusing on moral disengagement. Together with a publication from 1999 (Bandura, 1999) it develops and sets the stage for how the theory is to be used in the future. The articles focus on the morality of human beings.

"A theory of morality must specify the mechanisms by which people come to live in accordance with moral standards.” (Bandura et al., 1996, p. 364)

"People do not ordinarily engage in reprehensible conduct until they have justified to themselves the rightness of their actions." (Bandura et al., 1996, p. 365)

"People have little reason to be troubled by guilt or to feel any need to make amends for inhumane conduct if they reconstrue it as serving worthy purposes or if they disown personal agency for it.” (Bandura et al., 1996, p. 366)

"Selective activation and disengagement of personal control permit different types of conduct by persons with the same moral standards under different circumstances.” (Bandura, 1999, p. 194) 
Bandura (1999) also investigates the functioning of each of the eight mechanisms of moral disengagement. As can be seen in Table 1, these are described in relation to individuals. It is interesting to note that while the mechanisms are focused on individuals, the impacts of such behavior can cause problems for groups of individuals. For example, dehumanization of workers can lead to poor labor conditions.

$$
\text { *** Please insert Table } 1 \text { about here *** }
$$

"The disengagement of moral self-sanctions from inhumane conduct is a growing human problem at both individual and collective levels.” (Bandura, 1999, p. 193)

While moral disengagement has focused on the morality of individuals that does not exclude the possibility of viewing how groups of people that morally disengage affect their environment.

“Collective moral disengagement can have widespread societal and political ramifications by supporting, justifying, and legitimizing inhumane social practices and policies.” (Bandura et al., 1996, p. 372)

During the development of the theory data has been centered on individuals. For example, this was achieved by a study including 799 children (Bandura et al., 1996), explanations built on earlier research focusing on individuals' engagement in, and attitudes toward, detrimental behavior (Bandura, 1999), and a study including 564 children (Bandura et al., 2001). There exists, however, a close connection between collectives of individuals, and the individuals themselves.
"People do not operate as autonomous moral agents impervious to the social realities in which they are immersed. Moral agency is socially situated and exercised in particualrized ways depending on the life conditions under which people transact their affairs.” (Bandura, 1999, p. 207)

Bandura (1999) argues how the context can drive, or halt, moral disengagement. The quote above highlights that human beings cannot be seen as isolated entities, as is consistent with reciprocal determinism (Bandura, 1978). One such environment is the organization in which the individual works, but also the extended chain of actors in the supply chain. The "conditions under which people transact their affairs" thus extends to the supply chain, and it is reasonable to consider the supply chain as a part of the environmental influences. This is also how the theory is used by Bandura et al. (2000) discussing transgression in the downstream supply chain, and by Bandura (1999, p. 198) explaining diffusion of responsibility through subdivided routinized tasks. To make a distinction between behavior and environmental influences is not only done by Bandura (1978), but is also advocated in social sciences (see Sayer (1992, p. 213) discussing 'object', 'causal powers', 'conditions' and 'events'), and can be seen in SCM research (Eriksson, 2015).

\subsection{Application of the Theory: Focus on Individuals, but with Inconsistencies}

Investigating moral disengagement and corporate transgression should, according to the snapshot above, focus on how individuals disengage from their morals. Moral disengagement might be a consequence of the context, which is how the theory is used. 
"People do not operate as autonomous moral agents, impervious to the social realities in which they are enmeshed. [...] Moral actions are the product of the reciprocal interplay of cognitive, affective and social influences.” (Bandura, 2002, p. 102)

People behave more cruelly when it is easy to escape accountability, which in organizations is manifested with group decisions and hierarchical chains of command (Bandura, 2002, pp. 107-108), however, despite mainly focusing on individuals, Bandura et al. (2000) also try to apply moral disengagement to a corporation,

"In many cases corporations actively defend their interests in ways that would normally be unthinkable for common law breakers". (Bandura et al., 2000, p. 58)

The authors continue by arguing why moral disengagement can be applied to the corporation itself.

"First, the reciprocal causation operates among corporate modes of thinking, corporate behaviour and the environment." (Bandura et al., 2000, pp. 59-60)

"Second, a corporation can be viewed both as a social construction and as an agentic system with the power to realize intentions." Bandura et al., 2000, (p. 60)

"Third, corporate identity is crucial for the development and functioning of a corporation.” (Bandura et al., 2000, p. 60)

"Moreover, the practices of a corporation operate through selfregulatory mechanisms. These mechanisms regulate the allocation of resources in the pursuit of the goals and objectives of the corporate in accordance with its values and standards.” (Bandura et al., 2000, p. 60)

"When corporations engage in reprehensible conduct they are likely to do so through selective disengagement of moral self-sanctions." (Bandura et al., 2000, p. 60)

The first quote does not clarify if organizational thinking and behavior is the thinking of humans acting in an organization, or if the organization itself is attributed with these, otherwise human, abilities. The second and third quotes do not explain if or why moral disengagement is possible to apply to organizations. The fourth quote attributes organizations with human traits of having a self, goals, objectives, values, and standards. The fifth quote is based on the assumption that organizations have the ability to chose and engage in conduct, and that the organization has both morality and a self.

While it is often useful to see an organization as an entity of its own, which it also is in some legal terms, the justification for applying moral disengagement to the organization is clearly vague, and so are the reasons. The justifications rest on an assumption that human traits can 
be attributed to organizations through colloquial similarities in how organizations and individuals are described, not actual similarities in how they actually are. The reasons overlook the fact that moral disengagement rests on reciprocal determinisms, which already distinguishes between individuals and their environment. Focusing on the individuals in their professional situation would be more consistent with the theory, and can add to the analysis, without losing justification for using the theory. Bandura et al. (2000) actually focus on moral disengagement and individuals throughout the article, part from some exceptions, for example:

"Ford used different moral disengagement strategies to defend its highly controversial decision.” (Bandura et al., 2000, p. 61)

This quote is a description made by the authors of the reviewed article, addressing how Ford dealt with controversy of faulty gas tanks in the Ford Pinto. By exchanging "Ford" with "Managers at Ford" the theory is applied consistently with how it has been developed, and the need for fitting it to organizations seems to be superfluous.

\section{Analysis}

After reviewing these papers it is now possible to turn back to the research question and shed some light on the important topic here addressed.

RQ: If the theory moral disengagement is to be used in supply chain management, what considerations are necessary?

Based on the works of Bandura it can be determined that the theory only applies to human beings. It is developed through studies on humans, and rests on several traits we use to describe and understand humans. The paper by Bandura et al. (2000) is the only inconsistent use found by Bandura himself. As mentioned above, the motivation for using moral disengagement on organizations is not convincing, and the choice to do so did not even seem necessary for the paper itself.

Using the theory in SCM demands that we consider two possible applications of moral disengagement to supply chains. The first alternative is if the supply chain itself uses moral disengagement, the second is if it is applied to individuals in a supply chain.

The first alternative, applying moral disengagement directly to a supply chain, or the companies therein, is not supported with how the theory was developed, and must therefore be considered incorrect. If it is to be done it needs to be thoroughly explained how this is possible, including both the generalizability of the theory to a supply chain, and the attribution of human traits to a supply chain.

The second alternative, however, is supported by the theory and should be encouraged. Bandura (1978) includes the environment in reciprocal determinism, in which organizations and supply chains may be placed. To understand how the environment can influence moralality the work by Sayer (1992) can be of assistance. He outlines how the possible events that objects can generate are dependent on the context in which they occur. The context could both cause, and prevent, moral disengagement. Multiple mechanisms of moral disengagement are described through the context in which they are likely to manifest (Bandura et al., 1996). Plenty of examples of the theory successfully applied to organizational contexts are available. 
For examples, see theoretical overview by Johnson and Buckley (2014) focusing on organizational structure and moral disengagement. See also Eriksson and Svensson (2014) for research connecting moral disengagement with SCM.

Going forward some concerns still exist. It could be beneficial to investigate the mechanisms of moral disengagement in individuals prior to, and after the discovery, of misconduct connected to the supply chain. Is it possible that different mechanisms, or the same mechanisms of moral disengagement but to a different degree, are activated before and/or after the harmful effects are realized? This is important in order to understand how to encourage individuals to act morally, and to understand how they can try to avoid moral responsibility. In the short Ford reference above (Bandura et al., 2000), it is possible that certain mechanisms of moral disengagement allowed managers moral leeway to take decisions that would cause suffering, and that other mechanisms helped them escape moral responsibility ex post facto.

The definition of moral itself can be argued, but Bandura uses it in relation to what an individual considers to be right and wrong. This is what we must accept when using his theory. Bandura does not provide a clear definition of ethics, so we need to turn to other sources. Merriam-Webster's online encyclopedia provides the following definition: "ethic: rules of behavior based on ideas about what is morally good and bad”. Lewis (1985, p. 383) defines business ethics as "rules, standards, codes, or principles which provide guidelines for morally right behavior and truthfulness in specific situations", and Bishop (2013, p. 636) states "ethics concerns the moral behavior of individuals based on an established and expressed standard of the group".

Bandura is focused on morality, but research into organizations that use moral disengagement often refers to ethics (e.g., Bandura et al., 2000; Baron et al., 2014; Chowdhury and Fernando, 2014). Johnson and Buckley (2014, p. 6) blur the line between moral and ethics stating “...moral disengagement, a method by which individuals cognitively 'disconnect' the causal links between one's actions and unethical outcomes...”. Moore et al. (2012p. 2) make similar statements: “....an important driver of unethical behavior is an individual's propensity to morally disengage...", and "...allows those inclined to morally disengage to behave unethically without feeling distress...”. These comments imply that there is a direct connection between morality and ethics, which might be fallacious. True, if ethics are social constructs of right and wrong, and those constructs are based on reasoning from morality, they are likely aligned, but that is not necessarily the case.

To assume that reduced moral disengagement increases ethics assumes that there is little to no difference between the moral of the individual, and the values that are agreed upon as ethical. If these do not align it is not possible to improve ethics by reducing moral disengagement. For example, if individuals in a supply chain do not share the same views on right and wrong as is stipulated in ethical guidelines, they do not need to morally disengage in order to behave unethically. They could, as a matter of fact, behave morally according to themselves, while being unethical according to an ethical guideline. It is therefore important to keep a distinction between morality and ethics, and to be aware that one does not, by default, produce the other.

Several authors have argued that morality only can be attributed to human beings (Bevan and Corvellec, 2007; McMahon, 2008; Jensen, 2010). For authors in related fields this is not an 
issue, but if we only turn to Bandura to see how the theory is used, we might be misguided, as he himself applies it to both individuals, and non-individuals (e.g., organizations).

\section{Concluding Discussion}

The purpose of this paper has been to bring clarity into what moral disengagement should be used for, and what the challenges are if it is used outside of this framework. The conclusions are summarized in Section 5, Analysis, outlining how moral disengagement should, and should not be used. It has been established that moral disengagement is only to be used on human beings. The supply chain setting is interesting as it can provide an environment in which moral disengagement is activated, or deactivated. If moral disengagement should be used on the organization (or the supply chain) itself, for example as was done with the Ford Pinto case, this needs to be properly justified.

Moral disengagement holds much potential if it is used in SCM research. It could help to explain demoralizing processes in organizations (Jensen, 2010), and increase knowledge on how organizations can align their corporate social responsibility interests with individuals in the supply chain (Aguinis and Glavas, 2012).

Through this paper, researchers find guidance and confidence to use the theory of moral disengagement in SCM research. By better understanding the context constituted by the supply chain and its management it might be possible to influence moral disengagement of the individuals active inside the supply chain. This is, in turn, food for thought for management. Perhaps corporate social responsibility and sustainability in the supply chain should be improved by reducing the possibility for employers to morally disengage?

\section{References}

Aguinis, H. and Glavas, A., (2012). "What We Know and Don't Know About Corporate Social Responsibility: A Review and Research Agenda", Journal of Management, Vol. 38 No. 4, pp. 932-968.

Bandura, A., (1963). Social learning and personality development, Holt, Reinhart, and Winston, New York, NY.

Bandura, A., (1978). "The Self System in Reciprocal Determinism", American Psychologist, Vol. 33 No. 4, pp. 344-358.

Bandura, A., (1999). "Moral Disengagement in the Perpetration of Inhumanities", Personality and Social Psychology Review, Vol. 3 No. 3, pp. 193-209.

Bandura, A., Barbaranelli, C., Caprara, G.V. and Pastorelli, C., (1996). "Mechanisms of Moral Dissengagement in the Exercise of Moral Agency", Journal of Personality and Social Psychology, Vol. 71 No. 2, pp. 364-374.

Bandura, A., Caprara, G.V. and Zsolnai, L., (2000). "Corporate Transgressions through Moral Disengagement", Journal of Human Values, Vol. 6 No. 1, pp. 57-64.

Baron, R.A., Zhao, H. and Miao, Q., (2014). "Personal Motives, Moral Disengagement, and Unethical Decisions by Entrepreneurs: Cognitive Mechanisms on the "Slippery Slope"', Journal of Business Ethics, Vol. No.

Bevan, D. and Corvellec, H., (2007). "The impossibility of corporate ethics: for a Levinasian approach to managerial ethics", Business Ethics: A European Review, Vol. 16 No. 3, pp. 208-219.

Bishop, W.H., (2013). "The Role of Ethics in 21st Century Organizations", Journal of Business Ethics, Vol. 118 No. 3, pp. 635-637. 
Chowdhury, R.M.M.I. and Fernando, M., (2014). "The Relationships of Empathy, Moral Identity and Cynicism with Consumers' Ethical Beliefs: The Mediating Role of Moral Disengagement", Journal of Business Ethics, Vol. 124 No. 4, pp. 677-694.

Chugh, D., Kern, M.C., Zhu, Z. and Lee, S., (2014). "Withstanding moral disengagement: Attachment security as an ethical intervention", Journal of Experimental Social Psychology, Vol. 51 No., pp. 88-93.

Cooper, M.C., Lambert, D.M. and Pagh, J.D., (1997). "Supply Chain Management: More Than a New Name for Logistics", The International Journal of Logistics Management, Vol. 8 No. 1, pp. 1-14.

Egan, V., Hughes, N. and Palmer, E.J., (2015). "Moral disengagement, the dark triad, and unethical consumer attitudes", Personality and Individual Differences, Vol. 76 No., pp. 123-128.

Egels-Zandén, N., (2015). "Responsibility Boundaries in Global Value Chains: Supplier audit priotitizations and moral disengagement among Swedish firms", Journal of Business Ethics, Vol. No., pp. 1-38.

Eriksson, D., (2014). Moral (De)coupling: Moral Disengagement and Supply Chain Management, PhD Thesis, University of Borås, Borås, Sweden.

Eriksson, D., (2015). "Lessons on Knowledge Creation in Supply Chain Management", European Business Review, Vol. No., pp. 346-368.

Eriksson, D., Hilletofth, P. and Hilmola, O.-P., (2013a). "Linking moral disengagement to supply chain practices", World Review of Intermodal Transportation Research, Vol. 4 No. 2/3, pp. 207-225.

Eriksson, D., Hilletofth, P. and Hilmola, O.-P., (2013b). "Supply chain configuration and moral disengagement", International Journal of Procurement Management, Vol. 6 No. 6, pp. 718-736.

Eriksson, D. and Svensson, G., (2014). "The Process of Responsibility, Decoupling Point, and Disengagement of Moral and Social Responsibility in Supply Chains: Empirical Findings and Prescriptive Thoughts", Journal of Business Ethics, Vol. No., pp. 1-18.

Fassin, Y. and Van Rossem, A., (2009). "Corporate Governance in the Debate on CSR and Ethics: Sensemaking of Social Issues in Management by Authorities and CEOs", Corporate Governance: An International Review, Vol. 17 No. 5, pp. 573-593.

Festinger, L., (1957). A Theory of Cognitive Dissonance, Stanford University Press, Stanford, CA.

Fida, R., Paciello, M., Tramontano, C., Fontaine, R.G., Barbaranelli, C. and Farnese, M.L., (2014). "An Integrative Approach to Understanding Counterproductive Work Behavior: The Roles of Stressors, Negative Emotions, and Moral Disengagement", Journal of Business Ethics, Vol. No.

Forrester, J.W., (1958). "Industrial Dynamics: A Major Breakthrough for Decision Makers", Harvard Business Review, Vol. 36 No. 4, pp. 118-130.

Haggbloom, S.J., Warnick, R., Warnick, J.E., Jones, V.K., Yarbrough, G.L., Russell, T.M., Borecky, C.M., Mcgahhey, R., Powell, J.L.I., Beavers, J. and Monte, E., (2002). "The 100 most eminent psychologists of the 20th century.", Review of General Psychology, Vol. 6 No. 2, pp. 139-152.

Hume, D., (1777). An Enquiry Concerning the Principles of Morals, Project Gutenberg.

Hutchinson, D., Singh, J. and Walker, K., (2012). "An assessment of the early stages of a sustainable business model in the Canadian fast food industry", European Business Review, Vol. 24 No. 6, pp. 519-531.

Høgevold, N.M., (2011). "A corporate effort towards a sustainable business model: A case study from the Norwegian furniture industry", European Business Review, Vol. 23 No. 4, pp. 392-400. 
Jensen, T., (2010). "Beyond Good and Evil: The Adiaphoric Company", Journal of Business Ethics, Vol. 96 No. 3, pp. 425-434.

Johnson, J.F. and Buckley, M., (2014). "Multi-level Organizational Moral Disengagement: Directions for Future Investigation", Journal of Business Ethics, Vol. No.

Jones, T.M. and Ryan, L.V., (1997). "The Link Between Ethical Judgment and Action in Organizations: A Moral Approbation Approach", Organization Science, Vol. 8 No. 6, pp. 663-680.

Lewis, P.V., (1985). "Defining 'Business Ethics': Like Nailing Jello to a Wall", Journal of Business Ethics, Vol. 4 No. 5, pp. 377-383.

Lowson, R., (2001). "Analysing the Effectiveness of European Retail Sourcing Strategies", European Management Journal, Vol. 19 No. 5, pp. 543-551.

Martin, S.R., Kish-Gephart, J.J. and Detert, J.R., (2014). "Blind forces: Ethical infrastructures and moral disengagement in organizations", Organizational Psychology Review, Vol. No.

Mcmahon, C., (2008). "The ontological and moral status of organizations", Business Ethics Quarterly, Vol. 5 No. 3, pp. 541-554.

Miemczyk, J., Johnsen, T.E. and Macquet, M., (2012). "Sustainable purchasing and supply management: a structured literature review of definitions and measures at the dyad, chain and network levels", Supply Chain Management: An International Journal, Vol. 17 No. 5, pp. 478-496.

Milgram, S., (1974). Obedience to authority: An experimental view, Harper \& Row, New York, NY.

Moore, C., Detert, J.R., Treviño, L.K., Baker, V.L. and Mayer, D.M., (2012). "Why employees do bad things: moral disengagement and unethical organizational behavior", Personnel Psychology, Vol. 65 No. 1, pp. 1-48.

Samnani, A.-K., Salamon, S.D. and Singh, P., (2014). "Negative Affect and Counterproductive Workplace Behavior: The Moderating Role of Moral Disengagement and Gender", Journal of Business Ethics, Vol. 119 No. 2, pp. 235-244.

Sayer, A., (1992). Method in Social Science - A Realist Approach, 2nd ed. Routledge, London, $\mathrm{UK}$.

Treviño, L.K., Weaver, G.R. and Reynolds, S.J., (2006). "Behavioral Ethics in Organizations: A Review", Journal of Management, Vol. 32 No. 6, pp. 951-990.

Walker, K. and Laplume, A., (2014). "Sustainability fellowships: the potential for collective stakeholder influence", European Business Review, Vol. 26 No. 2, pp. 149-168.

Warburton, R.D.H. and Stratton, R., (2002). "Questioning the relentless shift to offshore manufacturing", Supply Chain Management: An International Journal, Vol. 7 No. 2, pp. 101-108.

Winter, M. and Knemeyer, M., (2013). "Exploring the integration of sustainability and supply chain management: Current state and opportunities for future inquiry", International Journal of Physical Distribution \& Logistics Management, Vol. 43 No. 1, pp. 18-38.

Zimbardo, P.G., (2007). The Lucifer Effect, How Good People Turn Evil, Rider Books, London, UK. 
Table 1: Examples of how moral disengagement is connected to individuals, from Bandura (1999, pp. 192-203)

Moral disengagement

Moral justification

Euphemistic labeling

Advantageous comparison

\begin{tabular}{l}
\hline Displacement of responsibility \\
\hline Diffusion of responsibility \\
\hline $\begin{array}{l}\text { Disregard or distortion of } \\
\text { consequences }\end{array}$
\end{tabular}

Dehumanization

\section{Example quote}

"People do not ordinarily engage in harmful conduct until they have justified to themselves the morality of their actions."

"People behave much more cruelly when assaultive actions are verbally sanitized than when they are called aggression.”

"Terrorists see their behavior as acts of selfless martyrdom by comparing them with widespread cruelties inflicted on the people with whom they identify."

"People will behave in ways they typically repudiate if a legitimate authority accepts responsibility for the effects of their conduct."

"The exercise of moral control is also weakened when personal agency is obscured by diffusing responsibility for detrimental behavior."

"When people pursue activities that are harmful to others for reasons of personal gain or social pressure, they avoid facing the harm they cause, or they minimize it."

"The strength of moral self-censure depends partly on how the perpetrators view the people they mistreat."

Attribution of blame

"In this process, people view themselves as faultless victims driven to injurious conduct by forcible provocation.” 